\title{
Recent Advances in Gastrointestinal Stent Development
}

\author{
Jin-Seok Park', Seok Jeong ${ }^{1,2}$ and Don Haeng Lee ${ }^{1,2,3}$ \\ ${ }^{1}$ Digestive Disease Center, Department of Internal Medicine, Inha University School of Medicine, Incheon, ${ }^{2}$ National Center of Efficacy Evaluation for \\ the Development of Health Products Targeting Digestive Disorders (NCEED), Incheon, ${ }^{3}$ Utah-Inha DDS \& Advanced Therapeutics Research Center, \\ Incheon, Korea
}

\begin{abstract}
Endoscopic stenting is increasingly being used in the management of gastrointestinal luminal obstruction, and has become the current treatment of choice for the palliation of blockage caused by malignant or benign growths. A variety of stents have been developed to enhance the efficacy of the procedure, and improvements are ongoing. In this article, we review the history of, and recent advances in, gastrointestinal stenting. We describe the rationale behind the design as well as the resulting outcome for each stent type.
\end{abstract}

Key Words: Stents; Drug-eluting stents; Endoscopy, gastrointestinal

\section{INTRODUCTION}

In the last decade, stents have been used as safe and effective alternatives to surgery or repetitive endoscopic procedures, to improve the quality of life for patients with various gastrointestinal (GI) diseases and disorders. Indications for the use of stenting have gradually expanded to include a variety of malignant strictures, obstructions, external compressions of the GI tract, malignant GI perforations and fistulae, and selected cases of benign stricture that are resistant to repeated balloon dilation or surgical bougienage. ${ }^{1-3}$ GI stents were originally designed as rigid, cylinder-like prostheses and, as a result, had poor efficacy and high adverse event rates, such as migration, obstruction, and perforation of the GI tract. ${ }^{4}$ In recent years, considerable advances have been made in the design of these stents, and several types of high-quality devices have been developed. ${ }^{5-7}$ In this review, we describe the history of GI stent usage for the treatment of digestive tract disease, and provide an update on the most recent technologies. Our discussion includes esophageal, gastroduodenal, biliary, and colonic stents.

Received: April 27, 2015 Accepted: May 6, 2015

Correspondence: Don Haeng Lee

Digestive Disease Center, Department of Internal Medicine, Inha University School of Medicine, 27 Inhang-ro, Jung-gu, Incheon 400-711, Korea

Tel: +82-32-890-2548, Fax: +82-32-890-2549, E-mail: ldh@inha.ac.kr

(c) This is an Open Access article distributed under the terms of the Creative Commons Attribution Non-Commercial License (http://creativecommons.org/ licenses/by-nc/3.0) which permits unrestricted non-commercial use, distribution, and reproduction in any medium, provided the original work is properly cited.

\section{HISTORICAL REVIEW OF STENT MANAGEMENT}

\section{Plastic stents}

GI stents are used to palliate patients with obstructions of the alimentary tract caused by malignancy. When patients are no longer candidates for surgery and cannot tolerate chemotherapy or radiation therapy, stenting has been used as an excellent palliative therapeutic modality by providing the patient immediate relief of symptoms. ${ }^{8}$ Historically, rigid polyvinyl plastic stent placement has been used to alleviate obstruction of the GI tract. ${ }^{9}$ Although effective in more than $80 \%$ of patients, plastic stents were associated with complications, such as migration, food impaction, and perforation in up to $10 \%$ of patients. ${ }^{10}$ Furthermore, the use of plastic stents was limited. The lumen of the alimentary tract often required dilation prior to stent placement because the plastic stent was of a fixed diameter. Contingent upon the tumor bulk location, friability, angulation, and tightness, insertions were often traumatic and the procedural complication rates were high. ${ }^{11}$

\section{Self-expandable metallic stents}

The use of self-expandable metallic stents (SEMSs) in the GI tract is one of the most notable advances in the history of therapeutic endoscopy. Since the introduction of uncovered SEMSs in the early 1990s, plastic stents have rarely been utilized for the palliation of malignant GI tract obstruction. SEMSs consist of woven, knitted, or laser-cut metal mesh cyl- 


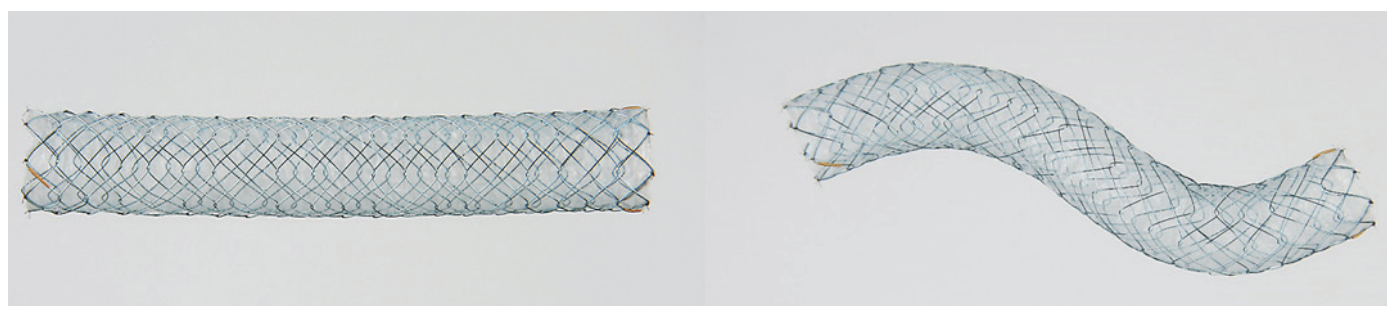

Fig. 1. Fully covered self-expandable metal stent (ComVi Stent; Taewoong). Adapted from http://www.stent.net, with permission from Taewoong. ${ }^{24}$

inders that exert self-expansive forces until they reach their maximum fixed diameter. They are generally packaged in a compressed form and constrained around a delivery device. ${ }^{3}$ Therefore, the SEMS can be inserted into a narrower opening, making dilation unnecessary and reducing the risks of perforation, obstruction, or migration, as can occur with plastic stents. ${ }^{9}$ Moreover, nitinol wire, which is a nickel titanium alloy with shape memory and super-elastic characteristics, greatly improved the utility of SEMS. Currently, the use of nitinol enables the development of variable designs, such as braided or knitted stents. ${ }^{12}$

According to a randomized controlled trial (RCT) of $42 \mathrm{pa}-$ tients by Knyrim et al., ${ }^{13}$ the use of SEMS was associated with significantly reduced stent-related adverse events compared to plastic prostheses in the palliative treatment of esophageal cancer ( 0 vs. $9, p<0.001$; the procedure-related mortality was $14 \%$ for plastic prostheses). In another RCT, 31 consecutive patients with inoperable esophageal cancer were randomized to receive either a SEMS (modified Gianturco metal stent) or a plastic prosthesis (Atkinson tube). Patients who received a SEMS had better palliation of dysphagia, shorter hospital days, and longer survival. ${ }^{14}$

SEMS have a longer patency compared to plastic stents because of their larger luminal diameters. In cases of biliary stenting, the diameter of a SEMS can be extended to 24 to 36 Fr through a relatively smaller ( 7 to $10 \mathrm{Fr}$ ) delivery system. ${ }^{15}$ The larger SEMS diameter leads to a lower incidence of bacterial growth in the stent, which is considered the main reason of biliary stent obstruction. On the other hand, the maximum diameter of plastic stents is limited to $12 \mathrm{Fr}$, because a plastic stent larger than $12 \mathrm{Fr}$ cannot be inserted through endoscopic working channels. Such relatively narrow lumens predispose plastic stents to occlusion by biliary sludge and/or bacterial biofilm formation, resulting in an average of 3 months of stent patency. ${ }^{16}$

\section{Covered self-expandable metallic stents}

Initial SEMS were uncovered and therefore had a risk of tumor ingrowth. ${ }^{17}$ The incidence of tumor ingrowth through the open mesh architecture is known to occur in 13\% of uncovered SEMS cases ${ }^{13}$ and epithelialization of uncovered stents arises within 3 to 6 weeks. ${ }^{18}$ In response to this, partially covered SEMSs, which have a membrane for the purpose of preventing tissue ingrowth into the lumen of the stent, ${ }^{19,20}$ were developed, and ultimately allow less ingrowth than uncovered SEMSs (3\% to $14 \%$ vs. $30 \%$ ). ${ }^{21-23}$ Soon after, it was observed that hypertrophic granulation at the uncovered ends of the stent prevented their repositioning or removal, making them usable only for palliation of GI tract malignancies. ${ }^{19}$ To overcome this drawback, fully covered self-expandable metal stents (FCSEMSs) have been developed (Fig. 1). ${ }^{24}$ While these stents can be effective in preventing tumor ingrowth, migration occurs frequently, compared to uncovered stents, because the cover on the outside prevents the embedding of the mesh in the tissue, thus reducing stent anchorage. ${ }^{25}$ One of the commonly used first-generation covered stents was the covered Gianturco Z stent (Wilson Cook Medical, Letchworth, England), a stainless steel stent covered by polyethylene. This stent had flared proximal and distal ends and central sharp barbs to anchor the stent in the tumor and prevent migration. However, migration still occurred in a large number of patients using this stent. ${ }^{26} \mathrm{~A}$ more recent modification includes covered stents that are specifically designed to prevent migration, with a partial cover, flared ends, or a double stent design. ${ }^{27-29}$ Such recent designs have led to an improvement in stent migration rates. With the latest stent design (Flamingo stent; Microvasive, Boston Scientific, Watertown, MA, USA), a migration rate of $\sim 5 \%$ has been described. ${ }^{26}$

\section{The future of GI stents}

GI stenting has progressed to the stage where this treatment is now considered minimally invasive therapy, with a high technical and clinical success rate. Moreover, GI stents improve the quality of life for patients with various GI diseases. However, a significant number of patients still require re-intervention for stent malfunctions, including obstruction, migration, and other related complications. Therefore, studies are ongoing to enhance the functions of stents, strengthen their merits, and reduce their drawbacks. As such, functional SEMSs have been developed. 


\section{Anti-migratory stents}

As mentioned above, migration is a major problem for FCSEMS. In this regard, several newly designed stents aimed at preventing FCSEMS migration have been developed. Anchoring components, such as flared ends and anchoring flaps, are typical of these recent designs. A flared end is commonly used to prevent migration. Tringali et al. ${ }^{30}$ reported a study on flared end FCSEMS (Niti-S; Taewoong Medical, Goyang, Korea) in patients with chronic pancreatitis. This has an expanded shape at both ends that prevents migration, while allowing for easier removal. In the literature, the Niti-S showed superior efficacy and a lower migration rate than conventional FCSEMS. ${ }^{30}$ Moon et al. ${ }^{31}$ recently also reported excellent results for the prevention of migration by using the Niti-S bumpy-type stent (Taewoong Medical) in patients with benign pancreatic duct strictures. In their study, ${ }^{32}$ patients with chronic pancreatitis were treated with flared-end FCSEMS (Fig. 2) ${ }^{24}$ and stent migration did not occur in any. ${ }^{31}$

A study using the dual-flap, with a fully covered metal Hanaro stent (M.I. Tech, Seoul, Korea), with four flaps at the proximal end, reported no distal migration during an indwell time of up to 6 months. ${ }^{32}$ In this study, the investigators also compared the anti-migratory effect of the anchoring flap and flared end, and found that none of the 22 patients in the anchoring flap group had stent migration, compared to $33 \%$ (seven of 21 , one proximal and six distal) in the flared end group $(p=0.004)$. They thus concluded that the anchoring flap is superior to the flared end with regard to stent migration. ${ }^{32}$ Mahajan et al. ${ }^{33}$ also reported a study on FCSEMS covered with Gore-Tex expanded polytetrafluoroethylene (Viabil; Conmed, Utica, NY, USA) in benign biliary strictures. This stent has serrated anchoring pins protruding from a section of the stent, significantly suppressing

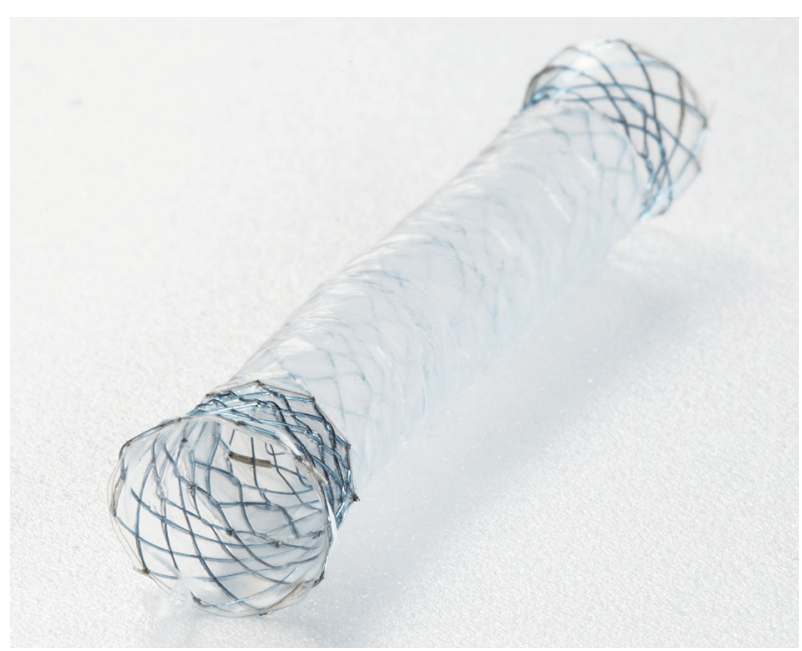

Fig. 2. Fully covered self-expandable metal stent with anti-migratory flared ends. Adapted from http://www.stent.net, with permission from Taewoong. ${ }^{24}$ its migration. However, stent removal was difficult. ${ }^{33}$

\section{Drug-eluting stents}

GI stent failures frequently occur due to the ingrowth and overgrowth of tumor cells or benign granulation tissue, despite the clinical improvement provided by the stent. The ingrowth and overgrowth could cause delayed stent occlusion and restricted patency, and result in shortened patient survival. Although covered SEMSs are designed to withstand tumor growth, occlusion is inevitable over time in most cases, because the polyurethane used is biodegraded in vivo by hydrolysis, oxidation, and continuous contact with GI tract content. ${ }^{34,35}$ Given these limitations, there have been efforts to develop drug-eluting stents (DESs), which are expected to prolong stent patency by adding anti-hyperplasia or anti-tumor functions. Paclitaxel is an extremely potent agent that causes the dose-dependent inhibition of proliferation of human epithelial gallbladder cells, fibroblasts, and pancreatic carcinoma cells in vitro. ${ }^{36}$ Because of this inhibitory effect, local delivery of paclitaxel using covered metallic biliary stents is now under investigation at many centers. Lee et al. ${ }^{37}$ introduced a metallic stent covered with a paclitaxel-incorporated membrane, and conducted a study to evaluate the safety of this device in the porcine biliary duct. Paclitaxel-containing biliary stents cause epithelial denudation and metaplasia, bile duct thickening, mucin hypersecretion, and fibrosis. However, no significant complications, including transmural necrosis and perforation, occurred in this study. With these results, the investigators concluded that a paclitaxel-incorporated metallic stent can be safely used in the normal bile duct. Another study examining local delivery into the bile duct compared paclitaxel-eluting SEMSs and control stents. Even though mucosal hyperplasia was noted in three of six dogs in the paclitaxel-eluting SEMS group, all experimental animals survived until death without evidence of jaundice. The authors concluded that paclitaxel-eluting SEMSs are safe in normal canine biliary tracts, and do not present technical difficulties. ${ }^{38}$ With these positive results in animals, human studies followed, a few of which demonstrated the antitumor effect of paclitaxel-eluting SEMS. ${ }^{39}$ However, a recent, prospective comparative study, using a metallic stent covered with a paclitaxel-incorporated membrane, did not show significant differences between paclitaxel-eluting SEMS and conventional FCSEMS, with respect to stent patency or patient survival..$^{40}$ Therefore, efforts to improve and demonstrate the effectiveness of DESs are ongoing. One of these entails selecting an adequate anti-tumor agent, depending on the nature of the cancer; in that regard, gemcitabine and 5-fluorouracil (5-FU) have gained attention.

Gemcitabine is the standard chemotherapeutic agent in advanced pancreatic and biliary tract cancer. However, it is hy- 

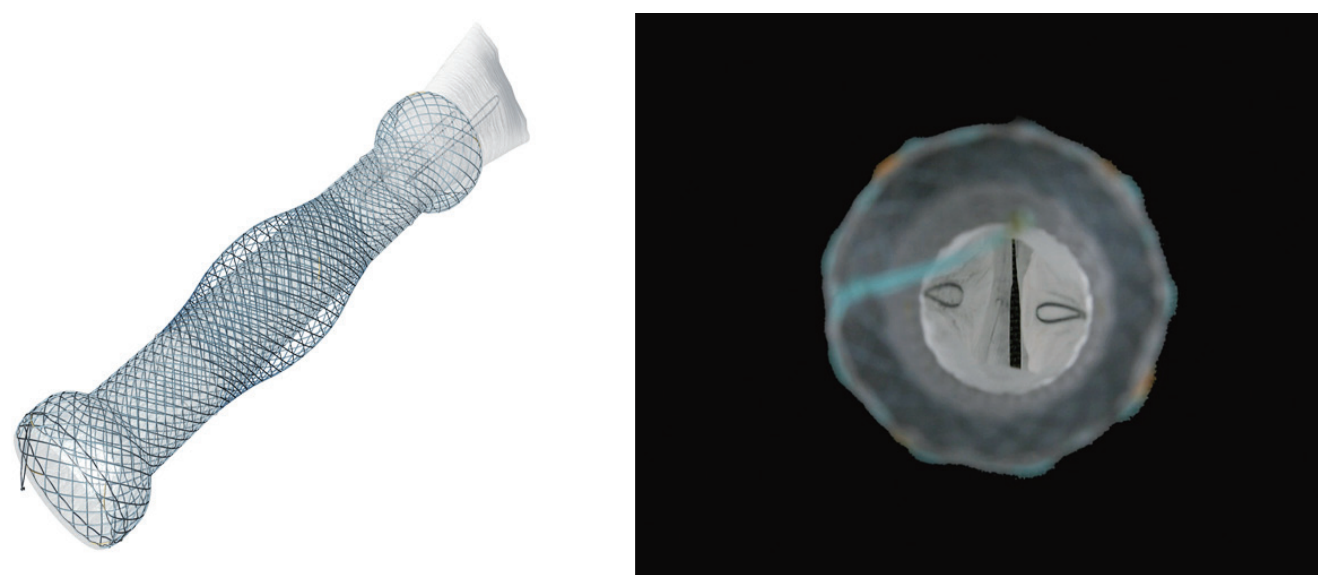

Fig. 3. Anti-reflux fully covered self-expandable metal stent with an anti-reflux valve at the distal end. Adapted from http://www.stent.net, with permission from Taewoong. ${ }^{24}$

drophilic and its local delivery is challenging, due to the initial burst of the gemcitabine. Prolonging gemcitabine release (over a 2-week period) is also unlikely. Therefore, a new design is required to allow prolonged drug elution through a broader contact surface between the stent and tumor, thereby maintaining a continuous and slow release of drug. Moon et al. ${ }^{41}$ introduced a gemcitabine-eluting stent using pullulan acetate. Pullulan is a natural polysaccharide that can be acetylated to varying degrees to form pullulan acetate, which has a greater drug-loading capacity. When pullulan acetate was layered onto polytetrafluoroethylene and applied as part of a gemcitabineloaded controlled-release membrane for drug-eluting nonvascular stents, the gemcitabine release lasted for 30 days.

Guo et al. ${ }^{42}$ developed a 5-FU-eluting esophageal stent. The 5-FU concentration in the stent-contacting segment of the esophagus is higher than in other areas, while its concentration in the mucosal layer is higher than that in the muscular layer. With the increased drug loading, the drug concentration in esophageal tissues increases, and cellular desquamation of the stent-contacting epithelial surface also becomes increasingly severe.

However, local drug delivery from the DES has a risk of damaging the adjacent normal digestive tract mucosa, as well as causing non-target organ toxicity and systemic exposure. Various studies are ongoing to determine the type and shape of stent membrane and appropriate drug concentration that will prevent stent-induced adverse events, and enable prolonged drug release. ${ }^{43,44}$

\section{Radioactive stents}

Brachytherapy in esophageal cancer takes longer to relieve the symptoms of dysphagia, but provides longer patency and fewer complications, compared to stent placement. ${ }^{45}$ The combination of stent insertion and brachytherapy is likely to be a feasible and safe palliative treatment strategy in patients with unresectable esophageal cancer. ${ }^{46}$ Therefore, radioactive stents have been developed, with the aim of combining the advantage of immediate relief of GI tract obstruction by stent insertion, with the longer-term benefits achieved through brachytherapy. Radioactive stents are loaded with iodine- 125 seeds. The inside of the stent is conventional metal, to facilitate insertion. The technical feasibility and safety of this new stent was identified in one animal study using rabbits. ${ }^{47}$ Moreover, results from a clinical RCT comparing 27 patients in a radioactive stent group and 26 in a control group showed significantly greater improvement in dysphagia grades in the radioactive stent group after 2 months. In addition, the median survival times were longer in the radioactive stent group $(p<0.001){ }^{48}$ Most studies on radioactive stents have been conducted on esophageal or biliary malignant obstruction, and the overall consensus was that the stents were relatively safe and easy to insert. However, these previous investigations involved too small a sample size to determine safety and feasibility. ${ }^{48,49}$ Therefore, large-scale studies are required before clinical application.

\section{Anti-reflux stents}

In inoperable GI tract cancers, SEMSs provide long-term GI tract patency and relieve progressive symptoms of obstruction, as they have larger lumens than plastic stents. However, refluxed content through the SEMS can cause various diseases, including ascending cholangitis or gastroesophageal reflux; this could also cause stent obstruction, by inducing biofilm formation or introducing undigested food. As a result, refluxed content tends to lower the quality of life. ${ }^{50,51}$ Therefore, there is a growing need for, and interest in, stents designed to prevent reflux. Stents with an attached anti-reflux valve are being developed (Fig. 3) ${ }^{24}$; studies on SEMSs with these valves have been conducted mainly in esophageal and biliary cancer patients. ${ }^{52,53}$ Early small studies in esophageal diseases sug- 
gested that these stents were effective at both relieving dysphagia and controlling reflux. ${ }^{54-56}$ However, the results of recently published studies evaluating anti-reflux stents were not always positive, because the attached valve often malfunctioned, depending on its design..$^{52,57,58}$ Anti-reflux valves designed to minimize the risk of stent malfunction led to decreased efficacy against reflux, while those designed for greater resistance interfered with natural stent patency. Therefore, a better anti-reflux valve design is needed.

\section{Shape-modified stents}

Modification of stent design is one strategy for reducing adverse effects and improving stent function and patency. There have been several modifications of stent design in the past 10 years. One interesting modification is a winged plastic stent with a small central lumen; this was developed based on the theory that tubular plastic stents contribute to biofilm formation and luminal occlusion. However, this modified stent did not show positive results compared to conventional SEMS..$^{59}$ Since endoscopic ultrasound (EUS) is frequently utilized for stent insertion, modification of the stent shape is also required for a successful procedure. A conventional SEMS has a high risk of migration and bile leakage during EUS-guided gallbladder drainage; accordingly, a SEMS has been developed to avoid these complications, by means of a dumbbell-shaped modification (AXIOS stent; Xlumena Inc., Mountain View, CA, USA). In one study reporting clinical results, AXIOS stents showed high technical (84.61\%) and clinical success (100\%) rates with respect to gallbladder drainage, and major complications did not occur. ${ }^{60}$ The ongoing effort to develop effective shape modifications to improve stents has achieved the desired results and has provided valuable information for future modifications.

\section{Biodegradable stents}

Biodegradable stents have shown promising results in recurrent benign strictures after ingestion of corrosive agents or iatrogenic endoscopic submucosal dissection. ${ }^{7,61,62}$ These stents consist of a braided structure of filaments made of absorbable polylactic acid polymers. Since the nature of the degradable stent does not require its removal, this can reduce hyperplastic tissue reactions and adverse events associated with stent removal, compared to SEMS. Additionally, it can be combined with antibacterial or antitumor agents, or equipped with drugeluting functions. ${ }^{63}$ Currently, stents constructed from biodegradable materials are ideal tools for treating benign strictures. Fry and Fleischer ${ }^{64}$ reported a case treated with a biodegradable esophageal stent (EsophaCoil; InStent, Eden Prairie, MN, USA) for benign esophageal strictures due to radiation injury. The investigators used a self-expanding coil-shaped biodegradable stent, which was effective in alleviating their patient's symp- toms. They concluded that such stents might be plausible treatment modalities for treating benign esophageal strictures. However, since the radial force of biodegradable stents is weaker than that of conventional metal stents, additional expansion of the lumen by using balloon dilatation is required after stent insertion. Biodegradable stents are still in the investigative stage; thus, long-term follow-up in many more cases is required to assess their efficacy.

\section{CONCLUSIONS}

The role of stenting in the management of patients with digestive tract obstruction has expanded in recent years to include the esophagus, stomach, small bowel, and colon. Recent advances in technology have improved stent patency and reduced stent-induced complications, resulting in an improved quality of life. However, GI stents continue to undergo design changes to address their limitations. Further technical refinements and studies to improve and demonstrate their efficacy are needed.

\section{Conflicts of Interest}

The authors have no financial conflicts of interest.

\section{REFERENCES}

1. Sabharwal T, Morales JP, Irani FG, Adam A; CIRSE: Cardiovascular and Interventional Radiological Society of Europe. Quality improvement guidelines for placement of esophageal stents. Cardiovasc Intervent Radiol 2005;28:284-288.

2. Siersema PD. Treatment options for esophageal strictures. Nat Clin Pract Gastroenterol Hepatol 2008;5:142-152.

3. ASGE Technology Committee, Varadarajulu S, Banerjee S, et al. Enteral stents. Gastrointest Endosc 2011;74:455-464.

4. Kochar R, Shah N. Enteral stents: from esophagus to colon. Gastrointest Endosc 2013;78:913-918.

5. McLoughlin MT, Byrne MF. Endoscopic stenting: where are we now and where can we go? World J Gastroenterol 2008;14:3798-3803.

6. Guo Q, Guo S, Wang Z. A type of esophageal stent coating composed of one 5-fluorouracil-containing EVA layer and one drug-free protective layer: in vitro release, permeation and mechanical properties. J Control Release 2007;118:318-324.

7. Tanaka T, Takahashi M, Nitta N, et al. Newly developed biodegradable stents for benign gastrointestinal tract stenoses: a preliminary clinical trial. Digestion 2006;74:199-205.

8. Dormann AJ, Eisendrath P, Wigginghaus B, Huchzermeyer H, Devière J. Palliation of esophageal carcinoma with a new self-expanding plastic stent. Endoscopy 2003;35:207-211.

9. Schumacher B, Lubke H, Frieling T, Haussinger D, Niederau C. Palliative treatment of malignant esophageal stenosis: experience with plastic versus metal stents. Hepatogastroenterology 1998;45:755-760.

10. Cusumano A, Ruol A, Segalin A, et al. Push-through intubation: effective palliation in 409 patients with cancer of the esophagus and cardia. Ann Thorac Surg 1992;53:1010-1014.

11. Fugger R, Niederle B, Jantsch H, Schiessel R, Schulz F. Endoscopic tube implantation for the palliation of malignant esophageal stenosis. Endoscopy 1990;22:101-104.

12. Castaño R, Lopes TL, Alvarez O, Calvo V, Luz LP, Artifon EL. Nitinol biliary stent versus surgery for palliation of distal malignant biliary ob- 
struction. Surg Endosc 2010;24:2092-2098.

13. Knyrim K, Wagner HJ, Bethge N, Keymling M, Vakil N. A controlled trial of an expansile metal stent for palliation of esophageal obstruction due to inoperable cancer. N Engl J Med 1993;329:1302-1307.

14. Roseveare CD, Patel P, Simmonds N, Goggin PM, Kimble J, Shepherd HA. Metal stents improve dysphagia, nutrition and survival in malignant oesophageal stenosis: a randomized controlled trial comparing modified Gianturco Z-stents with plastic Atkinson tubes. Eur J Gastroenterol Hepatol 1998;10:653-657.

15. Jaganmohan S, Lee JH. Self-expandable metal stents in malignant biliary obstruction. Expert Rev Gastroenterol Hepatol 2012;6:105-114.

16. Kim JH. Endoscopic stent placement in the palliation of malignant biliary obstruction. Clin Endosc 2011;44:76-86.

17. Song HY, Jung HY, Park SI, et al. Covered retrievable expandable nitinol stents in patients with benign esophageal strictures: initial experience. Radiology 2000;217:551-557.

18. Baerlocher MO, Asch MR, Dixon P, et al. Interdisciplinary Canadian guidelines on the use of metal stents in the gastrointestinal tract for oncological indications. Can Assoc Radiol J 2008;59:107-122.

19. Siersema PD, Hop WC, van Blankenstein M, Dees J. A new design metal stent (Flamingo stent) for palliation of malignant dysphagia: a prospective study. The Rotterdam Esophageal Tumor Study Group. Gastrointest Endosc 2000;51:139-145.

20. Kubba AK, Krasner N. An update in the palliative management of malignant dysphagia. Eur J Surg Oncol 2000;26:116-129.

21. van Boeckel PG, Siersema PD, Sturgess R, et al. A new partially covered metal stent for palliation of malignant dysphagia: a prospective follow-up study. Gastrointest Endosc 2010;72:1269-1273.

22. Bona D, Laface L, Bonavina L, et al. Covered nitinol stents for the treatment of esophageal strictures and leaks. World J Gastroenterol 2010;16: 2260-2264.

23. Verschuur EM, Repici A, Kuipers EJ, Steyerberg EW, Siersema PD. New design esophageal stents for the palliation of dysphagia from esophageal or gastric cardia cancer: a randomized trial. Am J Gastroenterol 2008; 103:304-312.

24. TaeWoong Medical. Taewoong Niti-S biliary stents [Internet]. Goyang: TaeWoong Medical; c2012 [cited 2015 May 14]. Available from: http:// www.stent.net.

25. Sreedharan A, Harris K, Crellin A, Forman D, Everett SM. Interventions for dysphagia in oesophageal cancer. Cochrane Database Syst Rev 2009;(4):CD005048.

26. Bartelsman JF, Bruno MJ, Jensema AJ, Haringsma J, Reeders JW, Tytgat GN. Palliation of patients with esophagogastric neoplasms by insertion of a covered expandable modified Gianturco-Z endoprosthesis: experiences in 153 patients. Gastrointest Endosc 2000;51:134-138.

27. Sabharwal T, Morales JP, Salter R, Adam A. Esophageal cancer: self-expanding metallic stents. Abdom Imaging 2005;30:456-464.

28. Sabharwal T, Hamady MS, Chui S, Atkinson S, Mason R, Adam A. A randomised prospective comparison of the Flamingo Wallstent and Ultraflex stent for palliation of dysphagia associated with lower third oesophageal carcinoma. Gut 2003;52:922-926.

29. Morgan R, Adam A. The radiologist's view of expandable metallic stents for malignant esophageal obstruction. Gastrointest Endosc Clin N Am 1999;9:431-435.

30. Tringali A, Familiari P, Mutignani M, Perri V, Costamagna G. Self-expandable, removable, fully covered metal stents to dilate common bile duct strictures secondary to chronic pancreratitis: preliminary results. Gastrointest Endosc 2010;71:AB169-AB170.

31. Moon SH, Kim MH, Park do H, et al. Modified fully covered self-expandable metal stents with antimigration features for benign pancreatic-duct strictures in advanced chronic pancreatitis, with a focus on the safety profile and reducing migration. Gastrointest Endosc 2010;72:8691.

32. Park do H, Lee SS, Lee TH, et al. Anchoring flap versus flared end, fully covered self-expandable metal stents to prevent migration in patients with benign biliary strictures: a multicenter, prospective, comparative pilot study (with videos). Gastrointest Endosc 2011;73:64-70.

33. Mahajan A, Ho H, Sauer B, et al. Temporary placement of fully covered self-expandable metal stents in benign biliary strictures: midterm evaluation (with video). Gastrointest Endosc 2009;70:303-309.

34. Khan I, Smith N, Jones E, Finch DS, Cameron RE. Analysis and evaluation of a biomedical polycarbonate urethane tested in an in vitro study and an ovine arthroplasty model. Part I: materials selection and evaluation. Biomaterials 2005;26:621-631.

35. Lee DK. Drug-eluting stent in malignant biliary obstruction. J Hepatobiliary Pancreat Surg 2009;16:628-632.

36. Kalinowski M, Alfke H, Kleb B, Dürfeld F, Joachim Wagner H. Paclitaxel inhibits proliferation of cell lines responsible for metal stent obstruction: possible topical application in malignant bile duct obstructions. Invest Radiol 2002;37:399-404.

37. Lee DK, Kim HS, Kim KS, et al. The effect on porcine bile duct of a metallic stent covered with a paclitaxel-incorporated membrane. Gastrointest Endosc 2005;61:296-301.

38. Lee SS, Shin JH, Han JM, et al. Histologic influence of paclitaxel-eluting covered metallic stents in a canine biliary model. Gastrointest Endosc 2009;69:1140-1147.

39. Suk KT, Kim JW, Kim HS, et al. Human application of a metallic stent covered with a paclitaxel-incorporated membrane for malignant biliary obstruction: multicenter pilot study. Gastrointest Endosc 2007;66: 798-803.

40. Jang SI, Kim JH, You JW, et al. Efficacy of a metallic stent covered with a paclitaxel-incorporated membrane versus a covered metal stent for malignant biliary obstruction: a prospective comparative study. Dig Dis Sci 2013;58:865-871.

41. Moon S, Yang SG, Na K. An acetylated polysaccharide-PTFE membrane-covered stent for the delivery of gemcitabine for treatment of gastrointestinal cancer and related stenosis. Biomaterials 2011;32: 3603-3610.

42. Guo SR, Wang ZM, Zhang YQ, et al. In vivo evaluation of 5-fluorouracil-containing self-expandable nitinol stent in rabbits: efficiency in long-term local drug delivery. J Pharm Sci 2010;99:3009-3018.

43. Jang SI, Kim JH, Kim M, et al. Porcine feasibility and safety study of a new paclitaxel-eluting biliary stent with a Pluronic-containing membrane. Endoscopy 2012;44:825-831.

44. Chung MJ, Kim H, Kim KS, Park S, Chung JB, Park SW. Safety evaluation of self-expanding metallic biliary stents eluting gemcitabine in a porcine model. J Gastroenterol Hepatol 2012;27:261-267.

45. Homs MY, Steyerberg EW, Eijkenboom WM, et al. Single-dose brachytherapy versus metal stent placement for the palliation of dysphagia from oesophageal cancer: multicentre randomised trial. Lancet 2004; 364:1497-1504.

46. Bergquist H, Johnsson E, Nyman J, et al. Combined stent insertion and single high-dose brachytherapy in patients with advanced esophageal cancer: results of a prospective safety study. Dis Esophagus 2012;25:410415.

47. Guo JH, Teng GJ, Zhu GY, He SC, Deng G, He J. Self-expandable stent loaded with $125 \mathrm{I}$ seeds: feasibility and safety in a rabbit model. Eur J Radiol 2007;61:356-361.

48. Guo JH, Teng GJ, Zhu GY, et al. Self-expandable esophageal stent loaded with 125I seeds: initial experience in patients with advanced esophageal cancer. Radiology 2008;247:574-581.

49. Liu Y, Liu JL, Cai ZZ, et al. A novel approach for treatment of unresectable extrahepatic bile duct carcinoma: design of radioactive stents and an experimental trial in healthy pigs. Gastrointest Endosc 2009;69(3 Pt 1):517-524.

50. Laasch HU, Marriott A, Wilbraham L, Tunnah S, England RE, Martin DF. Effectiveness of open versus antireflux stents for palliation of distal esophageal carcinoma and prevention of symptomatic gastroesophageal reflux. Radiology 2002;225:359-365.

51. Misra SP, Dwivedi M. Reflux of duodenal contents and cholangitis in 
patients undergoing self-expanding metal stent placement. Gastrointest Endosc 2009;70:317-321.

52. Homs MY, Wahab PJ, Kuipers EJ, et al. Esophageal stents with antireflux valve for tumors of the distal esophagus and gastric cardia: a randomized trial. Gastrointest Endosc 2004;60:695-702.

53. Hu B, Wang TT, Shi ZM, et al. A novel antireflux metal stent for the palliation of biliary malignancies: a pilot feasibility study (with video). Gastrointest Endosc 2011;73:143-148.

54. Köcher M, Dlouhy M, Neoral C, et al. Esophageal stent with antireflux valve for tumors involving the cardia: work in progress. J Vasc Interv Radiol 1998;9:1007-1010.

55. Davies RP, Kew J, Byrne PD. Treatment of post-stent gastroesophageal reflux by anti-reflux Z-stent. Cardiovasc Intervent Radiol 2000;23:487489.

56. Do YS, Choo SW, Suh SW, et al. Malignant esophagogastric junction obstruction: palliative treatment with an antireflux valve stent. J Vasc Interv Radiol 2001;12:647-651.

57. Kim DU, Kwon CI, Kang DH, Ko KH, Hong SP. New antireflux selfexpandable metal stent for malignant lower biliary obstruction: in vitro and in vivo preliminary study. Dig Endosc 2013;25:60-66.

58. McGrath JP, Browne M, Riordan C, Ravi N, Reynolds JV. Expandable metal stents in the palliation of malignant dysphagia and oesophagealrespiratory fistulae. Ir Med J 2001;94:270-272.

59. Schmidt A, Riecken B, Rische S, et al. Wing-shaped plastic stents vs. self-expandable metal stents for palliative drainage of malignant distal biliary obstruction: a randomized multicenter study. Endoscopy 2015; 47:430-436.

60. de la Serna-Higuera C, Pérez-Miranda M, Gil-Simón P, et al. EUSguided transenteric gallbladder drainage with a new fistula-forming, lumen-apposing metal stent. Gastrointest Endosc 2013;77:303-308.

61. Saito Y, Tanaka T, Andoh A, et al. Novel biodegradable stents for benign esophageal strictures following endoscopic submucosal dissection. Dig Dis Sci 2008;53:330-333.

62. Vandenplas Y, Hauser B, Devreker T, Urbain D, Reynaert H. A degradable esophageal stent in the treatment of a corrosive esophageal stenosis in a child. Endoscopy 2009;41 Suppl 2:E73.

63. Kwon CI, Ko KH, Hahm KB, Kang DH. Functional self-expandable metal stents in biliary obstruction. Clin Endosc 2013;46:515-521.

64. Fry SW, Fleischer DE. Management of a refractory benign esophageal stricture with a new biodegradable stent. Gastrointest Endosc 1997;45: 179-182. 